\title{
Comparison of Ropivacaine with Fentanyl vs Bupivacaine with Fentanyl for Postoperative Epidural Analgesia in Total Knee Arthroplasty: A Prospective, Randomized, Single-blinded Controlled Study
}

\author{
${ }^{1}$ Meenoti P Potdar, ${ }^{2}$ Ajay Tomar, ${ }^{3}$ Laxmi Kamat
}

\begin{abstract}
Aim: The primary aim of the study was to compare epidural ropivacaine with fentanyl and epidural bupivacaine with fentanyl for postoperative epidural analgesia after total knee arthroplasty (TKA). The secondary objective was to assess the outcomes of passive and active mobilizations postoperatively, requirement of rescue analgesia, and adverse effects, such as nausea vomiting, sedation, numbness, motor weakness, hypotension, and respiratory depression.
\end{abstract}

Materials and methods: After obtaining hospital ethics committee approval and written informed consent, 100 patients were randomly allocated to two groups of 50 each. Group B received $0.125 \%$ bupivacaine with fentanyl $(2 \mu \mathrm{g} / \mathrm{mL})$ epidurally for postoperative pain relief. Group $\mathrm{R}$ received $0.2 \%$ ropivacaine with fentanyl $(2 \mu \mathrm{g} / \mathrm{mL})$ epidurally for postoperative pain relief. Patients of American Society of Anesthesiologists (ASA) grades I to II of both sexes undergoing elective TKA and giving written consent were included in the study. Patients with coagulation disorders, history of spine surgery, vertebral deformities, and having contraindications for spinal analgesia were excluded from the study. All patients were preoperatively assessed and clinically evaluated thoroughly. They received conventional combined spinal epidural anesthesia followed by epidural infusion in the postoperative period of ropivacaine fentanyl or bupivacaine fentanyl as per the allocation. The postoperative epidural analgesia was supplemented with intravenous (IV) paracetamol $1 \mathrm{gm}$ TDS, and rescue analgesia, if needed, was given with IV tramadol $50 \mathrm{mg}$. All patients were monitored for postoperative pain by the visual analog scale (VAS), requirement of rescue analgesia, hemodynamic parameters, sedation scores, and adverse effects.

Keywords: Bupivacaine, Epidural, Fentanyl, Ropivacaine, Total knee arthroplasty.

How to cite this article: Potdar MP, Tomar A, Kamat L. Comparison of Ropivacaine with Fentanyl vs Bupivacaine with Fentanyl for Postoperative Epidural Analgesia in Total Knee Arthroplasty: A Prospective, Randomized, Single-blinded Controlled Study. Res Inno in Anesth 2017;2(2):51-57.

\footnotetext{
${ }^{1}$ Consultant, ${ }^{2}$ Senior Resident, ${ }^{3} \mathrm{Head}$

${ }^{1-3}$ Department of Anesthesia, Dr L H Hiranandani Hospital Mumbai, Maharashtra, India

Corresponding Author: Meenoti P Potdar, Consultant Department of Anesthesia, Dr L H Hiranandani Hospital Mumbai, Maharashtra, India, Phone: +919920627839, e-mail: meenoti@yahoo.com
}

\section{Source of support: Nil}

Conflict of interest: None

\section{INTRODUCTION}

Pain is by far one of the most common and distressing symptoms of disease, and all medical persons regard its relief as one of their main duties. An acute pain service must be available, while anesthesiologists must remain one of the main contributors for pain management. If pain is agony, relieving pain is ecstasy.

Effective pain management is a critical component of postoperative care and contributes to fewer postoperative complications, early mobilization, shortened hospital stay, and a better quality-of-life.

Achievement of adequate postoperative analgesia in a patient undergoing TKA is often a challenging task. ${ }^{1}$ Severe pain is common after TKA and can delay early commencement of physiotherapy; the most important determinant of successful postoperative knee rehabilitation. ${ }^{2}$ The current trend in postoperative pain is multimodal analgesia. ${ }^{3}$

Epidural opioids have been used, but the associated major side effects, such as sedation, itching, urinary retention, nausea, vomiting, and respiratory depression have limited its widespread use.

Bupivacaine has a well-defined role in regional anesthesia and analgesia for several years. Ropivacaine is a newer long-acting amide-linked local anesthetic agent. It is a pure $S$ enantiomer of propivacaine with greater differentiation between sensory and motor blocks and with better margin of safety due to reduced toxic potential.

This study is aimed at comparing the efficacy of these two local anesthetics at equipotent doses for epidural analgesia after TKA.

\section{AIMS AND OBJECTIVES}

The primary aim of the study was to compare epidural ropivacaine with fentanyl and epidural bupivacaine with fentanyl for postoperative epidural analgesia after TKA.

We also assessed the secondary outcomes of passive and active mobilizations postoperatively, requirement 
of rescue analgesia, and adverse effects, such as nausea, vomiting, sedation, numbness, motor weakness, hypotension, and respiratory depression.

\section{SETTING AND DESIGN}

This is a prospective, randomized, single-blinded, singlecentered comparative study of 100 patients undergoing unilateral or bilateral TKA.

\section{SAMPLE SIZE}

The sample size was calculated as per the pilot study of 10 cases from each group. Considering significance level (alpha level) of 0.05 and assuming the arithmetic mean difference (difference of averages of VAS between the groups) of 0.36 and standard deviation of 0.47 , two sample t-tests were applied to calculate power and sample size using Minitab16. With a power of $96 \%$, a sample size of 48 was effective. Hence, we decided to recruit 100 patients -50 in each group for the study.

\section{MATERIALS AND METHODS}

After obtaining hospital ethics committee approval and written informed consent, patients were randomly allocated to two groups of 50 each.

Group B received $0.125 \%$ bupivacaine with fentanyl ( $2 \mu \mathrm{g} / \mathrm{mL}$ ) epidurally for postoperative pain relief.

Group $\mathrm{R}$ received $0.2 \%$ ropivacaine with fentanyl ( $2 \mu \mathrm{g} / \mathrm{mL}$ ) epidurally for postoperative pain relief.

\section{Inclusion Criteria}

Patients of ASA grades I to II of both sexes undergoing elective TKA and giving written consent were included in the study.

\section{Exclusion Criteria}

Patients having severe cardiorespiratory illness, coagulation disorders, history of spine surgery, vertebral deformities, infection at local site, and with allergies to amide local anesthetics were excluded from the study.

\section{Preoperative Assessment}

All patients were preoperatively assessed for routine laboratory blood investigations, chest X-ray, 12-lead electrocardiogram (ECG), and dobutamine stress echo and cardiology evaluation.

Patients were kept fasting for 8 hours for solids and 4 hours for clear liquids prior to the surgery.

\section{Monitoring}

All patients were continuously monitored for heart rate $(\mathrm{HR})$, respiratory rate (RR), and oxygen saturation with a pulse oximeter and ECG. Noninvasive blood pressure monitoring was done for systolic blood pressure (SBP) and diastolic blood pressure (DBP) by automatic brachial oscillometry.

\section{Methods}

On the day of surgery, IV access was secured preoperatively with 20 G IV cannulae. Patients were preloaded with 500 mL of Ringer's lactate prior to spinal anesthesia. Patients were allocated to the respective groups by picking up of sealed envelopes by the staff nurse not included in the study.

All patients received combined spinal epidural anesthesia in sitting position, under all aseptic precautions, in the L2-3 or L3-4 intervertebral space. The intrathecal drug was given with 15 to $20 \mathrm{mg}$ of bupivacaine $0.5 \%$ heavy with $120 \mu \mathrm{g}$ buprenorphine. An epidural catheter (Portex Ltd., 16 G) was inserted and kept 3 to $5 \mathrm{~cm}$ into the epidural space after confirming with the loss-of-resistance technique to air. All patients were given oxygen supplementation through nasal cannulae at $2 \mathrm{~L} / \mathrm{min}$ postspinal anesthesia.

All patients were catheterized as per the surgical protocol. If required, the patients received IV midazolam $0.03 \mathrm{mg} / \mathrm{kg}$ for sedation.

A thigh tourniquet was used during surgery (320 $\mathrm{mm} \mathrm{Hg}$ on average). Tranexamic acid 0.5 to $1.0 \mathrm{gm} \mathrm{IV}$ was given at the discretion of the surgeon for reduction of surgical bleeding. After the completion of surgery, patients were transferred to the recovery room. The epidural infusion was started when the sensory block regressed to T12-L1. Continuous epidural infusion was started using syringe infusion pump with either $5 \mathrm{~mL} /$ hour of $0.125 \%$ bupivacaine $+2 \mu \mathrm{g} / \mathrm{mL}$ fentanyl or $8 \mathrm{~mL} /$ hour of $0.2 \%$ ropivacaine $+2 \mu \mathrm{g} / \mathrm{mL}$ fentanyl. The dose of the epidural infusion was titrated as per the patients pain scoring. Postoperative epidural analgesia was supplemented with IV paracetamol at $1 \mathrm{gm}$ TDS and rescue analgesia, if needed, was given with IV tramadol $50 \mathrm{mg}$.

All patients were given oxygen through nasal prongs at 1 to $2 \mathrm{~L} / \mathrm{min}$ on day 0 . Patients were followed up for postoperative pain relief until epidural catheter was removed.

The following were observed and noted:

- Postoperative pain was assessed by $10 \mathrm{~cm}$, horizontal VAS, where 10 corresponds to the most severe pain that the patient can imagine and 0 corresponds to no pain at all. Pain scoring was done 6 hourly on day 0 and for the next 2 days.

Day of surgery was labeled as day 0 (zero) and the next days as days 1 and 2. The VAS was assessed at rest, passive mobilization, and active mobilization. 
Assessment and restriction of mobilization was assessed on days 0,1 , and 2.

- Requirement of rescue analgesia (IV tramadol $50 \mathrm{mg}$ ).

- Hemodynamic monitoring was done 2 hourly after starting epidural infusion on day 0 and 6 hourly for the next 2 days. Pulse, blood pressure, and RR were noted.

- Sedation was checked by Ramsay sedation score, two hourly on day 0 and 6 hourly for next 2 days.

Ramsay sedation scale

- Patient is anxious and agitated or restless, or both

- Patient is cooperative, oriented, and tranquil

- Patient responds to commands only

- Patient exhibits brisk response to light glabellar tap or loud auditory stimulus

- Patient exhibits a sluggish response to light glabellar tap or loud auditory stimulus

- Patient exhibits no response

- Adverse effects, such as nausea and vomiting, numbness, and motor weakness were noted. As all patients had a urinary catheter, urinary retention was not taken into consideration. Hypotension and decreased urine output were assessed and treated with IV fluids. Motor weakness and numbness were treated by decreasing the rate of epidural infusion.

Vomiting was managed with IV ondansetron $4 \mathrm{mg}$ stat with TDS and pantoprazole $40 \mathrm{mg}$.

Sedation score, if more than 3, was managed by decreasing the rate of epidural infusion and supplementing with oxygen, if required.

\section{Statistical Analysis}

The data were entered using MS-Excel-2007 and analyzed using Statistical Package for the Social Sciences version 16 software. Following statistical tests of significance are used.

- Unpaired t-test-for comparison between two groups (for comparison of means between two groups, numerical data which are normally distributed).

- Mann-Whitney U-test-for comparison between two groups (for comparison of means between two groups, numerical data which are not normally distributed).

- Chi-square test (for comparison of proportions between two groups, categorical data).

\section{RESULTS}

\section{Demographic Data}

The demographic data for both the groups are comparable by chi-square test ( $p$-value $<0.05$ ) as shown in Table 1 .

\section{Hemodynamic Parameters}

Graph 1 shows the hemodynamic and the respiratory parameters during the postoperative period.
Table 1: Demographic distribution of the study cases

\begin{tabular}{llllll}
\hline & \multicolumn{2}{c}{ Group R } & \multicolumn{2}{c}{ Group B } & $p$-value \\
\hline Age & 62.6 & 7.285 & 63.36 & 6.154 & 0.554 \\
Sex & & & & & \\
F & 35 & $70 \%$ & 34 & $69 \%$ & \\
M & 15 & $30 \%$ & 16 & $31 \%$ & \\
Weight & 61.4 & 4.504 & 61.26 & 5.217 & 0.886 \\
Height & 159 & 7.827 & 159.72 & 7.799 & 0.646 \\
Side & & & & & \\
B & 24 & $48 \%$ & 24 & $48 \%$ & \\
U & 26 & $52 \%$ & 26 & $52 \%$ & \\
\hline
\end{tabular}

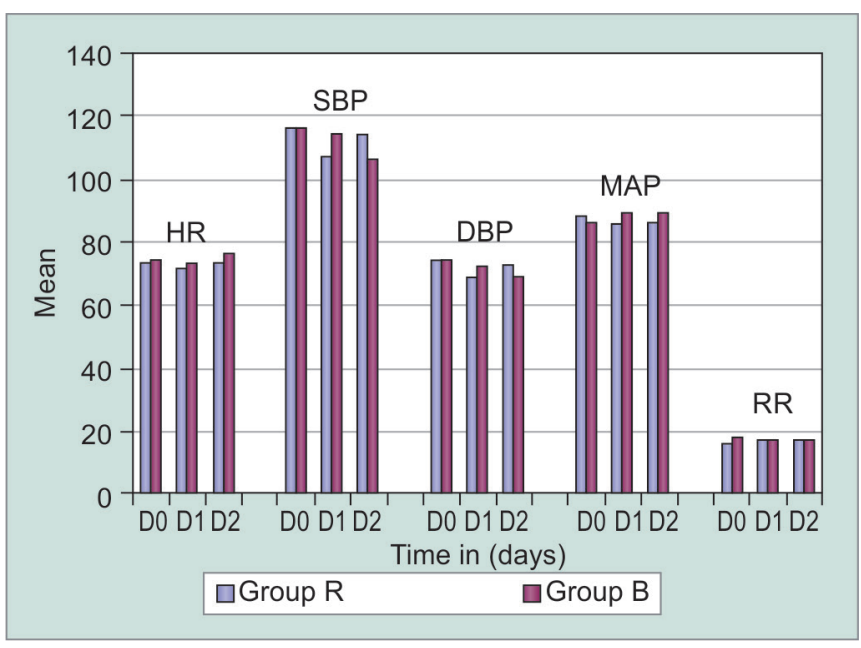

Graph 1: Comparison of hemodynamic RR between groups

The mean HR on day 0 in groups $R$ and $B$ was $73.75 \pm$ $8.76 / \mathrm{min}$ and $74.39 \pm 7.68 / \mathrm{min}$ (p-value 0.701$)$, day 1 was $71.764 \pm 7.31 / \mathrm{min}$ and $74.010 \pm 8.50 / \mathrm{min}(\mathrm{p}$-value 0.160$)$, and day 2 was $74.82 \pm 6.95 / \mathrm{min}$ and $75.33 \pm 6.51 / \mathrm{min}$ (p-value 0.706 ) respectively.

The mean SBP on day 0 in groups $\mathrm{R}$ and B was 116.86 \pm 6.73 and $116.86 \pm 6.73 \mathrm{~mm} \mathrm{Hg}$ (p-value 1.000), day 1 was $107.20 \pm 6.62$ and $114.80 \pm 7.07 \mathrm{~mm} \mathrm{Hg}$ (p-value 0.500), and day 2 was $114.80 \pm 7.07$ and $107.20 \pm 6.62 \mathrm{~mm} \mathrm{Hg}$ (p-value 0.432 ) respectively.

The mean DBP on day 0 in groups $\mathrm{R}$ and $\mathrm{B}$ was 74.24 \pm 3.39 and $74.24 \pm 3.39 \mathrm{~mm} \mathrm{Hg}$ (p-value 1.000), day 1 was $69.30 \pm 3.63$ and $72.92 \pm 3.37 \mathrm{~mm} \mathrm{Hg}$ (p-value 0.212), and day 2 was $72.92 \pm 3.37$ and $69.30 \pm 3.63 \mathrm{~mm} \mathrm{Hg}$ (p-value $0.657)$ respectively.

The mean MAP on day 0 in groups $\mathrm{R}$ and $\mathrm{B}$ was 89.07 \pm 7.58 and $86.83 \pm 6.29 \mathrm{~mm} \mathrm{Hg}$ (p-value 1.111), day 1 was $86.24 \pm 5.73$ and $89.89 \pm 6.68 \mathrm{~mm} \mathrm{Hg}$ (p-value 0.074$)$, and day 2 was $86.04 \pm 5.56$ and $89.49 \pm 6.16 \mathrm{~mm} \mathrm{Hg}$ (p-value $0.168)$ respectively.

The HR, SBP, DBP, and MAP on all days in both groups were comparable with unpaired t-test $(p<0.05$, significant).

The mean RR on day 0 in groups $\mathrm{R}$ and $\mathrm{B}$ was 15.70 $\pm 1.72 / \mathrm{min}$ and $17.87 \pm 0.82 / \mathrm{min}(\mathrm{p}$-value $<0.001)$, day 


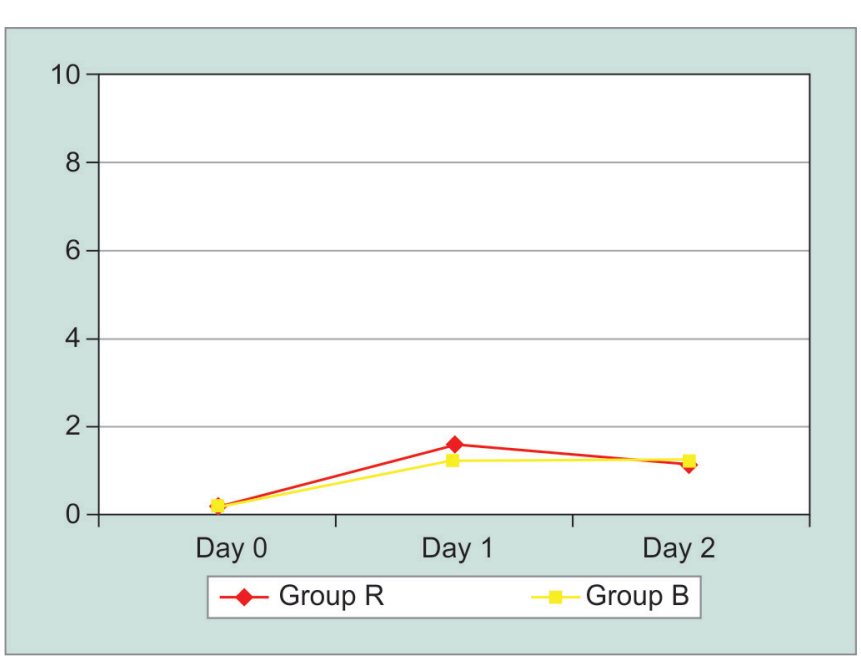

Graph 2: Comparison of VAS at rest

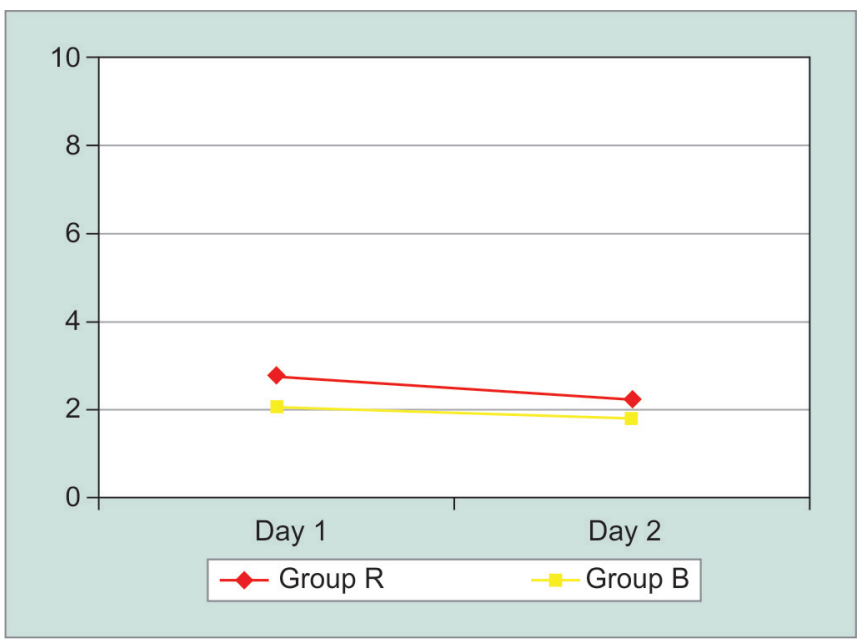

Graph 4: Comparison of VAS scores on active mobilization between groups

1 was $17.70 \pm 0.53 / \mathrm{min}$ and $17.62 \pm 0.71 / \mathrm{min}$ (p-value 0 . 539), and day 2 was $17.70 \pm 0.62 / \mathrm{min}$ and $18.08 \pm 0.63 /$ min (p-value 0.004 ) respectively.

There was a statistically significant difference in RR between the groups on days 0 and 2, with rates being lower in group $\mathrm{R}$ whereas rates on day 1 were comparable.

\section{The VAS for Pain}

The VAS scores are shown in the Graphs 2 to 4 at different time intervals in the post operative period.

The mean VAS at rest (Graph 2) on day 0 in group $R$ and group $B$ was $0.18 \pm 0.24$ and $0.16 \pm 0.25$ (p-value 0.733 ), day 1 was $1.59 \pm 0.66$ and $1.23 \pm 0.28$ ( $\mathrm{p}$-value $<0.001$ ), and day 2 was $1.15 \pm 0.18$ and $1.23 \pm 0.38$ (p-value 0.179 ) respectively, by Mann-Whitney U-test ( $<<0.05$, significant).

The VAS scores at rest were higher in group R compared with group B on day 1 and were statistically significant $(\mathrm{p}<0.05)$. On days 0 and 2 , scores were comparable. The VAS scores in group R at days 1 (Graph 3) and 2 (Graph 4)

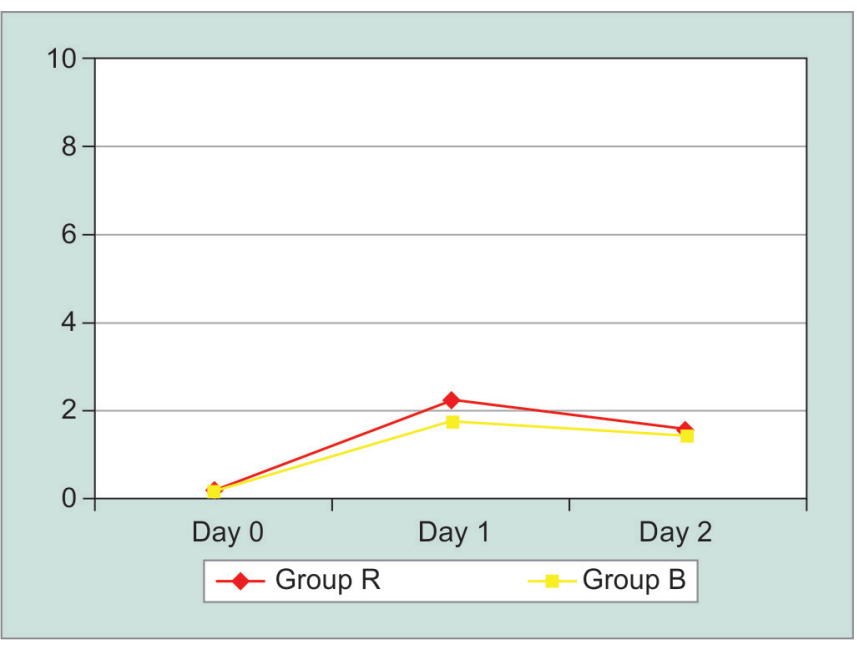

Graph 3: Comparison of VAS scores on passive mobilization between groups

were higher as compared with day 0 and were statistically significant $(p<0.05)$. In group $B$, scores on day 1 and 2 were higher than day 0 , but the difference was not statistically significant.

The mean VAS on passive mobilization on day 0 in groups $\mathrm{R}$ and $\mathrm{B}$ was $0.18 \pm 0.24$ and $0.16 \pm 0.25$ (p-value 0.733 ), day 1 was $2.28 \pm 0.72$ and $1.76 \pm 0.56$ (p-value 0.001 ), and day 2 was $1.15 \pm 0.24$ and $1.23 \pm 0.35$ (p-value 0.001 ) respectively, by Mann-Whitney U-test ( $\mathrm{p}<0.05$, significant).

The VAS scores on passive mobilization were higher in group $R$ compared with group $B$ on days 1 and 2 and were statistically significant $(p<0.05)$. On day 0 , scores were comparable between groups.

The VAS scores in both the groups at days 1 and 2 were higher as compared with day 0 and were statistically significant $(\mathrm{p}<0.05)$.

The mean VAS on active mobilization on day 1 in groups $\mathrm{R}$ and $\mathrm{B}$ was $2.75 \pm 0.78$ and $2.03 \pm 0.91$ (p-value $<0.001$ ), and day 2 was $2.18 \pm 0.30$ and $1.78 \pm 0.57$ (p-value $<0.001$ ) respectively, by Mann-Whitney U-test ( $<<0.05$, significant).

The VAS scores on active mobilization were higher in group $R$ than in group B on days 1 and 2 and were statistically significant $(\mathrm{p}<0.05)$.

\section{Rescue Analgesia}

The requirement of rescue analgesic was noted as shown in Table 2 on all the postoperative days.

Mean rescue analgesia requirement on other days was higher in group $\mathrm{R}$ than group $\mathrm{B}$, but the difference was comparable and not statistically significant by unpaired t-test ( $\mathrm{p}$-value $<0.05$, significant).

\section{Adverse Effects}

The incidence of adverse effects was comparable in both the groups as shown in Table 3. 
Comparison of Ropivacaine with Fentanyl vs Bupivacaine with Fentanyl

Table 2: Comparison of requirement of rescue analgesia between groups

\begin{tabular}{lllllll}
\hline $\begin{array}{l}\text { Rescue } \\
\text { analgesia }\end{array}$ & Groups & $n$ & Mean & $\begin{array}{l}\text { Standard } \\
\text { deviation }\end{array}$ & p-value & Significance \\
\hline Day 0 & R & 50 & 0 & 0 & & \\
& B & 50 & 0 & 0 & & \\
Day 1 & $\mathrm{R}$ & 50 & 0.72 & 1.05 & 0.205 & NS \\
& B & 50 & 0.48 & 0.81 & & \\
Day 2 & R & 50 & 0.16 & 0.37 & 0.569 & NS \\
& B & 50 & 0.12 & 0.33 & & \\
\hline
\end{tabular}

On Day 0 , there was no requirement of rescue analgesia in either of the groups; NS: Not significant

Table 4: Comparison of Ramsay sedation scores between groups

\begin{tabular}{lllllll}
\hline Sedation & & \multicolumn{5}{c}{ Standard } \\
score & Groups & $n$ & Mean & deviation & p-value Significance \\
\hline Day 0 & $\mathrm{R}$ & 50 & 1.960 & 0.0808 & 0.008 & $\mathrm{~S}$ \\
& $\mathrm{~B}$ & 50 & 2.016 & 0.1218 & & \\
Day 1 & $\mathrm{R}$ & 50 & 1.904 & 0.1414 & $<0.001$ & $\mathrm{~S}$ \\
& $\mathrm{~B}$ & 50 & 2.000 & 0 & & \\
Day 2 & $\mathrm{R}$ & 50 & 2.000 & 0 & & \\
& $\mathrm{~B}$ & 50 & 2.000 & 0 & & \\
& & & & & & \\
\hline
\end{tabular}

S: Significant

Incidence of nausea and vomiting on days 0,1 , and 2 was comparable and not statistically significant by chisquare test $(\mathrm{p}<0.05)$.

The incidence of motor weakness although higher in group B was comparable and not statistically significant.

The incidence of numbness although higher in group $\mathrm{R}$ was comparable and not statistically significant.

The sedation scores were monitored in the post operative period abd are shown in Table 4.

On days 0 and 1 , the sedation scores in group $B$ were slightly higher than group $\mathrm{R}$ and was statistically significant by Mann-Whitney U-test ( $\mathrm{p}<0.05$, significant). But the mean scores in both groups were within normal clinical range. On day 2, the mean sedation score in group $\mathrm{R}$ and group $\mathrm{B}$ was equal.

\section{DISCUSSION}

Postoperative pain is a major concern after TKA. ${ }^{4}$ Cooper and Turner ${ }^{5}$ found that TKA was possibly more painful and required greater amount of analgesia than total hip arthroplasty (THA).

Pang et $\mathrm{al}^{6}$ found three reasons why pain after TKA is more than after THA.

- The knee joint receives nerves from both the lumbar segments and conus medullaris of the spinal cord.

- In case of TKA, there is tourniquet-induced postischemic pain.

- The knee joint is surrounded by less soft tissue than the hip joint. This leads to higher tension or pressure
Table 3: Comparison of adverse effects between groups

\begin{tabular}{lllll}
\hline \multirow{2}{*}{ Adverse effect } & & $\begin{array}{l}\text { Group R } \\
(n=50)\end{array}$ & $\begin{array}{l}\text { Group B } \\
(n=50)\end{array}$ & $p$-value \\
\hline Nausea and & Day 0 & 13 & 12 & 0.279 NS \\
vomiting & Day 1 & 14 & 13 & 0.822 NS \\
\multirow{4}{*}{ Motor weakness } & Day 2 & 2 & 1 & 0.558 NS \\
& Day 0 & 3 & 4 & 0.695 NS \\
& Day 1 & 4 & 8 & 0.218 NS \\
Numbness & Day 2 & 2 & 5 & 0.240 NS \\
& Day 0 & 4 & 3 & 0.695 NS \\
& Day 1 & 8 & 5 & 0.372 NS \\
& Day 2 & 5 & 3 & $0.461 \mathrm{NS}$ \\
\hline
\end{tabular}

NS: Not significant

due to swelling or edema following surgical trauma in knee operations and, thus, causes pain.

It is severe in $60 \%$ of patients and moderate in $30 \% .{ }^{4}$ When inadequately treated, it intensifies reflex responses, which can cause serious complications, such as pulmonary complications, thromboembolism, hyperdynamic circulation, and increased oxygen consumption. ${ }^{7}$ Moreover, it hinders early intense physical therapy, the most influential factor for good postoperative knee rehabilitation. ${ }^{8,9}$

Poor mobilization, in turn, results in adhesions, capsular contracture, and muscle atrophy; all of which may delay or permanently impair the ultimate functional outcome.$^{10}$ Few studies have assessed the influence of the postoperative analgesic technique on the knee rehabilitation after TKA.

When compared with conventional IV or intramuscular opioid treatments, epidural analgesia has advantages ${ }^{11-13}$ of better postoperative pain relief and, thus, the ability to perform physiotherapy. This leads to rapid achievement of all postoperative rehabilitative milestones and thus, requires a shorter hospital stay.

Thus, we decided to use postoperative epidural infusion to take care of pain following TKA.

Polley et $\mathrm{al}^{14}$ did a study to assess the relative analgesic potencies of epidural bupivacaine and ropivacaine by determining their respective minimum local analgesic concentrations. They found that the minimum local analgesic concentration of ropivacaine was $0.111 \% \mathrm{wt} / \mathrm{vol}(95 \%$ confidence interval, $0.100-0.122$ ) and the minimum local analgesic concentration of bupivacaine was $0.067 \% \mathrm{wt} /$ vol (95\% confidence interval, 0.052-0.082). Ropivacaine was significantly less potent than bupivacaine, with a potency ratio of 0.6 (95\% confidence interval, $0.49-0.74$ ).

So, we decided to compare equipotent concentrations of ropivacaine $(0.2 \%)$ and bupivacaine $(0.125 \%)$ for our study.

The present study comprised 100 patients of ASA grades I and II, of either sexes undergoing TKA (bilateral or unilateral). 
In our study, we observed that demographic characteristics were comparable. There was equal distribution of unilateral and bilateral TKA between the groups.

The hemodynamic parameters on all days in both groups were comparable. Lierz et $\mathrm{al}^{15}$ did a study to compare epidural injections of ropivacaine $0.2 \%$ with bupivacaine $0.125 \%$ in outpatients suffering from chronic low back pain. They found that hemodynamics in the groups were comparable.

There was a statistically significant difference in RR between the groups on days 0 and 2 with rates being lower in group $\mathrm{R}$, whereas rates on day 1 were comparable. Although the lower RR in group $R$ are statistically significant, the difference is not clinically significant as mean values in both groups are within normal physiological range on all days and do not indicate respiratory depression. None of the patients in either group required either reduction of infusion rate or discontinuation of epidural infusion as RR was never less than 10/minute.

Macias et a $1{ }^{16}$ compared epidural ropivacaine $(0.15 \%)$ and fentanyl $(5 \mu \mathrm{g} / \mathrm{mL})$, with bupivacaine $(0.1 \%)$ and fentanyl $(5 \mu \mathrm{g} / \mathrm{mL})$ for post-thoracotomy analgesia and found no significant difference in RR between groups.

The VAS scores for pain at rest were significantly low in group $B$ than in group $R$ on day 1 , whereas scores on days 0 and 2 were comparable. The VAS scores on passive and active mobilizations were significantly lower in group B than in group $R$ on days 1 and 2, whereas scores on day 0 were comparable. Thus, bupivacaine provided better analgesia than ropivacaine both at rest and during mobilization.

On comparing VAS scores between days, we found that scores in both groups were higher on days 1 and 2 . On day 0 , patients were at rest and given passive mobilization once; hence, scores were lower. The reason for the higher pain scores on days 1 and 2 is that the patient is given active mobilization and made to stand and walk. Muldoon et $\mathrm{al}^{17}$ did a comparison study between epidural infusion of ropivacaine $0.2 \%$ and bupivacaine $0.2 \%$ for postoperative pain after TKA. They found that ropivacaine group had slightly higher VAS scores than bupivacaine group, which was similar to our study. But the number of patients requiring rescue analgesia was comparable in both the groups and not statistically significantly.

Jørgensen et $\mathrm{al}^{18}$ investigated the effect of continuous epidural $0.2 \%$ ropivacaine vs $0.2 \%$ bupivacaine on postoperative pain, motor block, and gastrointestinal function after abdominal hysterectomy and found no significant differences between groups in number of patients requesting supplementary analgesics, which was similar to our study.

The incidence of nausea and vomiting was comparable in both groups. Macias et $\mathrm{al}^{16}$ compared thoracic epidural ropivacaine- $0.15 \% /$ fentanylof $5 \mu \mathrm{g} / \mathrm{mL}$ with bupivacaine $-0.125 \% /$ fentanyl of $5 \mu \mathrm{g} / \mathrm{mL}$ for post-thoracotomy analgesia and found that incidence of vomiting in both groups was comparable.

Incidence of motor weakness was comparable between groups on days 0,1 , and 2 and did not make a statistically significant difference. Jørgensen et $\mathrm{al}^{18}$ investigated the effect of continuous epidural $0.2 \%$ ropivacaine vs $0.2 \%$ bupivacaine on postoperative pain, motor block, and gastrointestinal function after abdominal hysterectomy. They found no significant differences in motor block between groups.

Incidence of numbness was comparable between groups on days 0,1 , and 2 and did not make a statistically significant difference.

Owen et $\mathrm{al}^{19}$ compared ropivacaine $0.075 \%$ and bupivacaine $0.075 \%$ with fentanyl $2 \mu \mathrm{g} / \mathrm{mL}$ for labor analgesia and found no difference in sensory blocking characteristics.

In our study, the sedation scores were significantly higher in group B than in group $\mathrm{R}$ on days 0 and 1 , whereas the scores on day 2 were comparable. But, the mean scores of 1.960 and 1.904 on days 0 and 1 in group $R$ and 2.016 and 2 on days 0 and 1 in group $B$ do not make clinically significant difference between groups. Furthermore, no patient in either group had a score more than 3 and neither required reduction of the rate nor discontinuation of epidural infusion for excessive sedation or any other treatment. Macias et $\mathrm{al}^{16}$ also had comparable sedation scores in their study on postthoracotomy analgesia with epidural ropivacaine fentanyl and bupivacaine fentanyl.

\section{CONCLUSION}

We concluded that the quality of analgesia after TKA produced by epidural bupivacaine/fentanyl is better than ropivacaine/fentanyl infusion, though the requirement of rescue analgesia is comparable between groups.

Both epidural analgesia and rescue analgesic requirements were higher on mobilization on postoperative day 1 with active mobilization. Hemodynamics, respiratory dynamics, and sedation scores were comparable and within normal clinical range. The incidence of other adverse effects was comparable between groups.

\section{REFERENCES}

1. Bernard JM, Hommeril JL, Passuti N, Pinaud M. Postoperative analgesia by intravenous clonidine. Anesthesiology 1991 Oct;75(4):577-582.

2. Capdevila X, BartheletY, BibouletP, Ryckwaert Y, RubenovitchJ, d'Athis F. Effects of perioperative analgesic technique on the surgical outcome and duration of rehabilitation after major knee surgery. Anesthesiology 1999 Jul;91(1):8-15.

3. Kissin I. Preemptive analgesia. Anesthesiology 2000 Oct;93(4): 1138-1143. 
4. Bonica, J. Postoperative pain. In: Bonica J, editor. The management of pain. 2nd ed. Philadelphia (PA): Lea \& Febiger; 1990. p. 461-480.

5. Cooper DW, Turner G. Patient-controlled extradural analgesia to compare bupivacaine, fentanyl, and bupivacaine with fentanyl in the treatment of postoperative pain. Br J Anaesth 1993 May;70(5):503-507.

6. Pang WW, Hsu TC, Tung CC, Hung CP, Chang DP, Huang MH. Is total knee replacement more painful than total hip replacement. Acta Anaesthesiol Sin 2000 Sep;38(3):143-148.

7. Kehlet H. Surgical stress: the role of pain and analgesia. Br J Anaesth 1989 Aug;63(2):185-195.

8. Shoji H, Solomonow M, Yoshino S, D'Ambrosia R, Dabezies E. Factors affecting postoperative flexion in total knee arthroplasty. Orthopaedics 1990 Jun;13(6):643-649.

9. Ryu J, Saito S, Yamamoto K, Sano S. Factors influencing the range of motion in total knee arthroplasty. Bull Hosp Joint Dis 1993 Summer;53(3):35-40.

10. Akeson WH, Amiel D, Abel MF, Garfin SR, Woo SL. Effects of immobilization on joints. Clin Orthop Relat Res 1987 Jun;219:28-37.

11. Williams-Russo P, Sharrock NE, Haas SB, Insall J, Windsor RE, Laskin RS, Ranawat CS, Go G, Ganz SB. Randomized trial of epidural versus general anaesthesia: outcomes after primary total knee replacement. Clin Orthop Relat Res 1996 Oct;331:199-208.

12. Mahoney OM, Noble PC, Davidson J, Tullos HS. The effect of continuous epidural analgesia on postoperative pain, rehabilitation, and duration of hospitalisation in total knee arthroplasty. Clin Orthop Relat Res 1990 Nov;260:30-37.
13. Pati AB, Perme DC,Trail M, Henry PK, Bryan WJ. Rehabilitation parameters in total knee replacement patients undergoing epidural vs. conventional analgesia. J Orthop Sports Phys Ther 1994 Feb;19(2):88-92.

14. Polley LS, Columb MO, Naughton NN, Wagner DS, van de Ven CJM. Relative analgesic potencies of ropivacaine and bupivacaine for epidural analgesia in labor: implications for therapeutic indexes. Anesthesiology 1999 Apr;90(4): 944-950.

15. Lierz P, Gustorff B, Markow G, Felleiter P. Comparison between bupivacaine $0.125 \%$ and ropivacaine $0.2 \%$ for epidural administration to outpatients with chronic low back pain. Eur J Anaesthesiol 2004 Jan;21(1):32-37.

16. Macias A, Monedero P, Adame M, Torre W, Fidalgo I, Hidalgo F. Randomized, double-blinded comparison of thoracic epidural ropivacaine, ropivacaine/fentanyl, or bupivacaine/fentanyl for postthoracotomy. Anaesth Analg 2002 Nov;95(5):1344-1350.

17. Muldoon T, Milligan K, Quinn P, Connolly DC, Nilsson K. Comparison of extradural infusion of ropivacaine or bupivacaine for prevention of postoperative pain after total knee replacement. Br J Anaesth 1998 May;80(5):680-681.

18. Jørgensen H, Fomsgaard JS, Dirks J, Wetterslev J, Dahl JB. Effect of continuous epidural $0.2 \%$ ropivacaine vs $0.2 \%$ bupivacaine on postoperative pain, motor block and gastrointestinal function after abdominal hysterectomy. Br J Anaesth 2000 Feb;8(2):144-150.

19. Owen MD, Thomas JA, Smith T, Harris LC, D'Angelo R. Ropivacaine $0.075 \%$ and bupivacaine $0.075 \%$ with fentanyl $2 \mu \mathrm{g} / \mathrm{mL}$ are equivalent for labor epidural analgesia. Anaesth Analg 2002 Jan;94(1):179-183. 